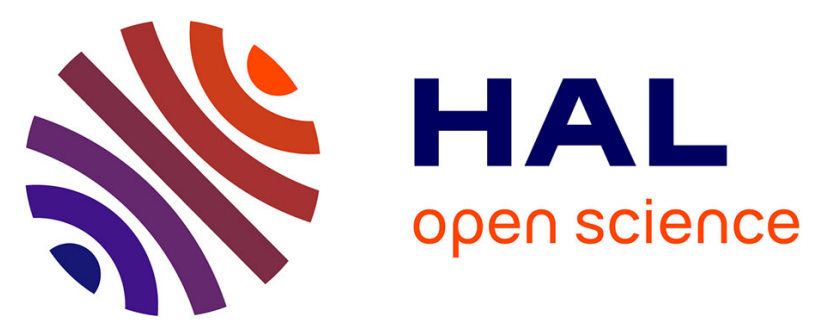

\title{
Distinct and combined effects of disciplinary composition and methodological support on problem solving in groups
}

Malte Schöfer, Nicolas Maranzana, Améziane Aoussat, Giacomo Bersano, Stéphanie Buisine

\section{To cite this version:}

Malte Schöfer, Nicolas Maranzana, Améziane Aoussat, Giacomo Bersano, Stéphanie Buisine. Distinct and combined effects of disciplinary composition and methodological support on problem solving in groups. Creativity and Innovation Management, 2018, 27 (1), pp.102-115. 10.1111/caim.12258 . hal-01798054

\section{HAL Id: hal-01798054 \\ https://hal.science/hal-01798054}

Submitted on 23 May 2018

HAL is a multi-disciplinary open access archive for the deposit and dissemination of scientific research documents, whether they are published or not. The documents may come from teaching and research institutions in France or abroad, or from public or private research centers.
L'archive ouverte pluridisciplinaire $\mathbf{H A L}$, est destinée au dépôt et à la diffusion de documents scientifiques de niveau recherche, publiés ou non, émanant des établissements d'enseignement et de recherche français ou étrangers, des laboratoires publics ou privés. 


\title{
Distinct and combined effects of disciplinary composition and methodological support on problem solving in groups
}

\author{
Malte Schöfer ${ }^{1,2}$ | Nicolas Maranzana ${ }^{1}$ | Améziane Aoussat ${ }^{1}$ | Giacomo Bersano ${ }^{3}$ | \\ Stéphanie Buisine ${ }^{1}$
}

\author{
${ }^{1}$ Laboratoire Conception de Produits et \\ Innovation (LCPI), Arts et Métiers ParisTech, \\ Paris, France \\ ${ }^{2}$ P3 Group, Schwerzenbach, Switzerland \\ ${ }^{3}$ Active Innovation Management (AIM), \\ Antony, France \\ Correspondence \\ Malte Schöfer, P3 Group, Sonnenbergstrasse \\ 41, 8603 Schwerzenbach, Switzerland. \\ Email: malte.schoefer@gmx.net
}

\begin{abstract}
Several reasons for the use of multidisciplinary teams composed of individuals with natural science and engineering background in problem-solving processes exist. The most important are the integration of science-based technologies into products and processes, and benefits for the problem-solving process thanks to new knowledge and new perspectives on problems. In this study we analyse the implications of interdisciplinary (science - engineering) group problem solving from a managerial as well as from a cognitive perspective. We then report on an experiment investigating the impact of problem-relevant disciplinary group composition and methodological support on the problem-solving process and its outcome. The findings of the experiment have managerial, theoretical, and pedagogical implications related to early phases of New Product/Process Design processes in high-technology and scientific knowledge-related domains.
\end{abstract}

\section{1 | INTRODUCTION}

The benefits of knowledge held by natural scientists for the development of innovative products and processes is evident in activities like, for example, biologically inspired design (e.g., Fayemi, Maranzana, Aoussat, \& Bersano, 2014). Moreover, the need for interdisciplinary problem solving for the development of innovative products and services is evident for Open Innovation Processes and Structures, like, for example, Idea Competitions and Innovation Networks (Marais, 2010) that are adopted by an increasing number of companies (Chesbrough, 2003). Some recent research suggests that novel perspectives on problems are sometimes more beneficial than the mere introduction of new idea generation stimuli (Chan, Dow, \& Schunn, 2015). As early as in the 1970s it was found that cognitive styles and strategies are related to the educational background of designers and scientists (Field, 1971; Lawson, 1979). In order to profit from such diverse perspectives and strategies, social mechanisms which prevail in monodisciplinary design teams (Cross \& Clayburn Cross, 1995) and which are amplified in multidisciplinary teams (e.g. Gebert, Boerner, $\&$ Kearney, 2006) must be taken into account.

The purpose of this paper is to report on a quantitative experiment investigating the impact of problem-relevant disciplinary group composition-monodisciplinary teams composed of participants with a life science background against multidisciplinary teams where participants with an engineering background join-and of methodological supportin terms of intuitive or logical approaches-on the process of group problem solving in knowledge-intensive domains as well as on the creative output of that process. The results of that experiment as well as its managerial, theoretical, and pedagogical implications are discussed.

\section{2 | LITERATURE REVIEW}

\section{1 | Technology convergence and increased interdisciplinarity in new product and process development (NPPD)}

Modern product and service systems are becoming increasingly complex and integrate knowledge and technologies from more and more distinct disciplines (Qureshi, Gericke, \& Blessing, 2013; Tomiyama, 2006). The need to integrate expertise from different engineering and natural science disciplines arises from trends like system miniaturization, increased quality requirements, higher product or service functionality, and product life cycle issues like end-of-life treatment (Tomiyama, 2006). Conventional top-down design processes predominantly divide the design task into smaller, often monodisciplinary tasks. As a consequence, strong relationships between these sub-tasks due to physical laws which affect several disciplinary domains are not taken into account by current processes (Erden et al., 2008; Tomiyama, 2006). Especially when the integration of a technology causes tradeoff problems related to, for example efficiency or costs, a need for basic mutual understanding of the concepts-e.g. cause-and-effect relationships (Yoshioka et al., 2004)-of other involved disciplines 
arises (Batzias \& Siontorou, 2012). However, several studies (Chulvi, Gonzalez-Cruz, Mulet, \& Aguilar-Zambrano, 2013; Gericke \& Blessing, 2011) reveal that interdisciplinary collaboration in design started to be discussed in the literature on design methodology only recently.

The importance of interdisciplinarity in NPPD has been proven by several authors. In industry, cross-functional interfaces between research departments and product development units, including direct personal contact in cross-functional teams, have been found to be beneficial. They increase a unit's capacity to assimilate and integrate new information, they reduce product development times (Clark \& Fujimoto, 1987; Cohen \& Levinthal, 1990) and they increase the level of creativity of generated ideas (Alves, Marques, Saur, \& Marques, 2007). One main argument for the value of multidisciplinary team composition is that it entails information diversity, which has been found to be important for team performance and team effectiveness (Jehn, Northcraft, \& Neale, 1999). In addition, background diversity in groups is supposed to bring forth an increased variety of ways to process information (Hinsz, Tindale, \& Vollrath, 1997). Moreover, multidisciplinary team composition is suitable for the application of extradomain knowledge for the resolution of problems by functionally diverse individuals that are not capable of codifying this very knowledge (Berry \& Broadbent, 1987), a prerequisite for the explicit transfer between teams.

With the increasing application of Open Innovation processes and structures in industry, interdisciplinary teams are supposed to work in collaborative frames, where the provided time for team building, joint problem analysis, and idea generation is very limited or-in the case of Innovation Networks, where problem settings are posted to a pool of problem solvers via an internet portal (Marais, 2010)-virtually non-existent. So-called "hackathons" (Olson et al., 2017) are one example where collaborative problem solving occurs in physically co-located teams. Within this concept of workshops, life scientists, engineers, and computer scientists work together on technological innovations during typically one or two days. Even though Olson et al. have found this collaborative framework to be fruitful, there is also research (Kane, Argote, \& Levine, 2005) that suggests that members of a group are more likely to apply superior knowledge to a task at hand that stems from an individual from the same social group, social integration being a process that would require much larger collaborative time frames.

\subsection{Implications of interdisciplinarity on the group level}

In order to understand how interdisciplinary NPPD processes can be methodologically supported, the impact of multidisciplinary group composition on the mechanisms of reasoning in teams as well as in individuals must be understood. Research in this respect has been carried out mainly in the fields of cognitive and management science.

Disciplinary diversity or cross-functionality in teams-the terms will be used synonymously here-are defined as the degree to which members of a team differ with regard to their disciplinary or functional background (Jackson, May, \& Whitney, 1995; Milliken \& Martins, 1996). Those types of diversity in teams are supposed to cause informational diversity (Jehn et al., 1999) and value diversity (Jackson et al., 1995) among the team members. According to Gebert et al. (2006), informational and value diversity lead to several types of conflicts, the most important being relationship conflict, value conflict, and task conflict (Gebert et al., 2006). Relationship conflicts are based on emotional tensions between group members and will not be discussed further here. Value conflicts relate to differing or opposing perceptions regarding the outcome of the team process (Gebert et al., 2006). They have been found to reduce the effectiveness and efficiency of a team (Jehn et al., 1999). Task conflicts describe situations in which there is disagreement on what procedures and processes to choose in order to fulfil a certain task (Pelled, Eisenhardt, \& Xin, 1999).

Whereas relationship conflicts and value conflicts are considered undesirable phenomena in team processes, research has provided mixed results regarding the evaluation of task conflict (Van Knippenberg \& Schippers, 2007). Unmanaged and hence manifested conflicts have detrimental effects on group performance (De Dreu, De Vries, \& Weingart, 2003; Jehn, 1997; Jehn et al., 1999). They can reduce cooperation and thus induce dissipation of energy during team work (Baron, 1991). However, when carefully managed in order to limit their impact, some conflicts have been found to bear the potential to enhance group performance (Gruenfeld, Mannix, Williams, \& Neale, 1996; Tjosvold, Meredith, \& Wong, 1998). They may lead to reduced conformity pressure and increased generation of alternative solutions to a problem, thus improving decision-making performance (Schwenk \& Valacich, 1994). As carefully managed and thus limited conflicts are perceived to have a positive impact on group performance, several methodological approaches for conflict induction and management in groups have been developed.

Related to conflicts in multidisciplinary teams are communication and comprehension barriers caused by incoherent interpretive schemes (Dougherty, 1992; Fleck, 1979), such as formalities, goals, perceptions, and languages. One solution to problems induced by incoherent interpretative schemes and unshared frames of reference (Van Knippenberg \& Schippers, 2007) within multifunctional and multidisciplinary teams are shared mental models (Hinsz et al., 1997). Mental models refer to "organized knowledge structures that allow individuals to interact with their environment [...] to predict and explain the behavior of the world around them [,] to recognize and remember relationships among components [and] to construct expectations for what is likely to occur next" (Mathieu, Heffner, Goodwin, Salas, \& CannonBowers, 2000, p. 274). Further functions of mental models are "descriptions of system purpose [and] explanations of system functioning" (Rouse \& Morris, 1985, p. 7). Shared mental models in a team have several advantages. First, they help to discover conflicts which are due to divergent personal perceptions of a problem, thus making those conflicts explicit (Hinsz et al., 1997). Second, during creative problem-solving tasks, shared mental or problem models lead to a reduction of the time required for consensus building, facilitate the elaboration and extension of conceptual ideas, and improve the coordination of group members (Mumford, Feldman, Hein, \& Nagao, 2001). In order to be beneficial for interdisciplinary design tasks, the mere quality of a shared mental model in terms of accuracy with individual models and high sharedness is not sufficient. The team's capacity to enact the shared model, i.e. to use it effectively in order to solve the design goal by managing conflicting requirements, has been found to be of equal importance (Dong, Kleinsmann, \& Deken, 2013). 


\section{3 | Conflict management methods and techniques in groups}

In order to perform the induction and the management of conflicts, which seem to be at the same time beneficial and harmful to group performance, several approaches have been developed. Two methods or techniques that are described and tested in the literature are dialectical inquiry and devil's advocacy (Mason, 1969; Schwenk, 1990).

Based on a meta-analysis of 16 experiments, Schwenk (1990) argues for the value of devil's advocacy and-to a lesser degree-dialectical inquiry. However, Nemeth, Brown, and Rogers (2001) found that artificial dissent in groups, introduced by devil's advocacy, contrary to genuine dissent does not significantly stimulate the generation of more solutions. Furthermore, original dissent has been found to be more effective than contrived dissent in keeping group information search balanced (Schulz-Hardt, Jochims, \& Frey, 2002).

\subsection{Conflicts and conflict management methods in individual reasoning}

From a cognitive science perspective, the parallel development of $a$ priori incongruent (Finke, Ward, \& Smith, 1992; Koestler, 1964), opposite, antithetic (Rothenberg, 1983, 1987) and hence somewhat conflicting concepts and their synthesis has been identified as one main characteristic of creative thought under laboratory conditions (Finke et al., 1992; Rothenberg, 1987) as well as in historical case studies of, for example, Albert Einstein and Niels Bohr (Rothenberg, 1983).

Widely used approaches to induce conceptual-in particular performance-related-conflicts and their resolution in creative reasoning are methods of TRIZ (orthographic transcription from Russian TРИЗ: Теория Решения Изобретательских Задач meaning Theory of Inventive Problem Solving [TIPS)] (Altshuller, 1996). The TRIZ complex also includes derived methods like Advanced Systematic Inventive Thinking (ASIT) (Horowitz, 1999) and Unified Structured Inventive Thinking (USIT) (Sickafus, 1997), which share several underlying principles:

- First of all, the approaches can be categorized as analytical, i.e. a considerable-often the main-part of the creative process consists in the analysis and modelling of the problem.

- Second, the concept of the ideality of the searched solution plays an important role. In TRIZ, ideality is defined as the ratio between the benefits of a solution as numerator and the negative sideeffects of the solution as well as the effort to realize it as denominator. In A/USIT, the ideality of a solution increases with the degree to which it can be obtained without changing the given problem setting.

- Third, the analysis of required functions, undesired negative sideeffects and their systematic attribution to the behaviour and structure of elements present in the problem setting is characteristic of those approaches.

- Fourth, all approaches to some extent describe design problems as some sort of conflict. In TRIZ, those conflicts consist in sets of a priori conflicting evaluation parameters of a system (Technical contradiction, e.g. "The power generated by a combustion engine must be increased without increasing the engine's fuel consumption") or in sets of opposed values of an object's structural parameters (Physical contradiction, e.g. "An engine's cylinder capacity should be increased in order to generate more power and it should be reduced in order to reduce fuel consumption"). In A/ USIT, those conflicts are circumscribed in the Qualitative Change condition (Horowitz, 1999; Sickafus, 1997).

Besides methods for the modelling of engineering design problems, the TRIZ complex also provides sets of heuristics for problem solving. The heuristics consist in strategies that were found to have been used by other designers for overcoming similar conflicts in the past.

\section{3 | HYPOTHESES}

In modern product and service design processes, the integration of science-related knowledge, especially for the resolution of trade-off problems, is of increasing importance. Likewise, since the beginning of the Open Innovation era, the input of engineers to problem solving in the life science sector is increasingly required. In order to facilitate the integration of extra-disciplinary knowledge and perspectives, creative problem solving in multidisciplinary teams can be considered essential. Interdisciplinarity as well as cross-functionality have been found to engender several types of conflicts. Carefully managed and embedded into a shared team mental model, those conflicts-much like conceptual conflicts in individual reasoning-have the potential to increase a group's problem-solving performance. Methodological approaches known for their capacity to induce and overcome conceptual conflicts are tools of the TRIZ complex. To the best of the authors' knowledge, the value of TRIZ methodology for mono- and interdisciplinary creative problem solving in a scientific-knowledge based domain has not yet been tested.

From that the following research question can be formulated: What is the impact of problem relevant disciplinary group composition and the applied problem-solving methodology on creative problem solving in knowledge-intensive domains, and are these impacts-to some extent-interdependent? This question leads to the following three hypotheses:

Hypothesis 1. Heterogeneous group composition in terms of disciplinary background and the resulting problem-relevant knowledge and perspective diversity impact the process $(\mathrm{H} 1 \mathrm{a})$ and outputs $(\mathrm{H} 1 \mathrm{~b})$ of creative problem solving of groups in knowledge-intensive domains.

Hypothesis 2. The methodological framework which is used in order to facilitate and support creative group problem solving impacts the process $(\mathrm{H} 2 \mathrm{a})$ and outputs $(\mathrm{H} 2 \mathrm{~b})$ of creative problem solving of groups in knowledge-intensive domains.

Hypothesis 3. There exists a mediating effect between disciplinary group composition and the applied methodological approach with regard to the creative group problem solving process $(\mathrm{H} 3 \mathrm{a})$ and its output $(\mathrm{H} 3 b)$. 
In order to test these hypotheses, a laboratory experiment was set up. The experiment is described in the following sections.

\section{4 | METHOD}

Teams composed of three students were asked to generate creative solutions to an ill-structured medical sector problem by following a generic problem-solving process characterized by problem definition, problem analysis, (divergent) idea generation, and (convergent) solution generation.

The conditions under which the groups engaged in the problemsolving process differed along two dimensions, a disciplinary one and a methodological one. There were 11 monodisciplinary groups. Nine of those groups were composed of three members with a life-science background (LS). Two groups, which served as controls, were composed of three members with a mechanical engineering background (ME). The nine multidisciplinary groups were composed of two members with a life-science and one member with a mechanical engineering background (L2M). Furthermore, half of the teams (10), previous to the problem-solving task, had been trained in Brainstorming and Mindmapping, which are considered instances of intuitive (Shah, Kulkarni, \& Vargas-Hernandez, 2000) general creativity techniques (GT). The other half (10) had followed a training in TRIZ and USIT, which are regarded as logical (Shah et al., 2000), rational (Cross, 2008) problem-solving approaches (TD = TRIZ and derivatives). The classification of the 20 groups according to the two conditional dimensions is synthesized in Figure 1.

\section{1 | Participants}

As one goal of the experiment consisted in the investigation of the impact of disciplinary group composition in terms of disciplinary and knowledge diversity, two sets of participants took part in the experiment. The first group consisted of 45 graduate students from Ecole de Biologie Industrielle. This school is an engineering school, the students of which have followed both undergraduate and graduate studies in the fields of biology, biotechnology, pharmacology, and medicine. Hence the students had an academic background in life sciences (LS). The second group of participants was composed of 15 graduate students from Arts et Métiers ParisTech, an engineering school specialized in the education of mechanical and industrial engineers. These participants had followed both undergraduate as well as graduate classes in

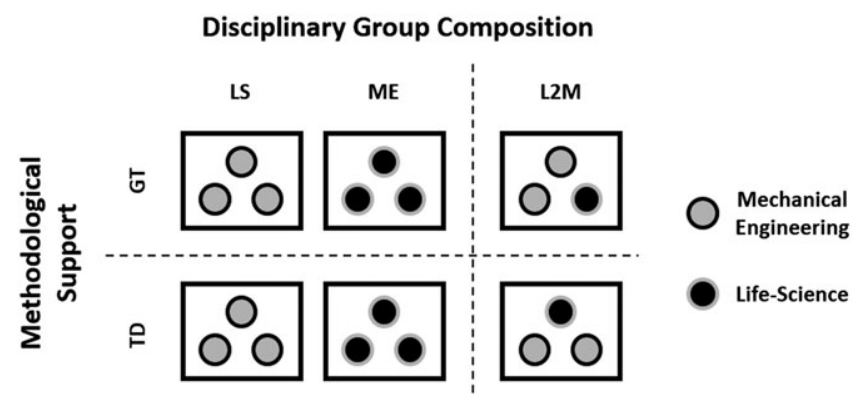

FIGURE 1 Group classification along two dimensions-disciplinary group composition and methodological support the field of mechanical engineering (ME). All 60 participants were at similar stages of professional education and validated a certain part of their innovation classes in exchange for their participation.

\section{2 | Training}

In order to compare the impact of rational analytical design methodology and of relevant general creativity methods on the process of creative group problem solving and its products, the participants were divided into two groups. Half of the participants (23 with LS background and seven with ME background) took part in 4.5-hour training in Brainstorming and Mindmapping, which are both instances of intuitive general creativity techniques (GT). The other half of the participants (22 with LS background and eight with ME background) took part in 4.5-hour training in basic concepts of TRIZ and its derivatives as rational creativity methods (TD).

The training in the general creativity techniques consisted in an introduction to Brainstorming (Osborn, 2009) and Mindmapping (Buzan, 1984; Kokotovich, 2008). During the training, fundamental principles of the creative process and analogical problem solving were briefly introduced. Further, basic principles and rules of Brainstorming were explained. Then, the documentation of ideas on concept sheets was explained. That introduction to theoretical aspects of Brainstorming was followed by the participants' application of the method to a problem of their choice. After that, the concept of Mindmapping after Buzan (1984) was presented. After the introduction of different types of keywords as elements of a Mindmap, the advantages of that method such as visual support and stimulation of associations were explained. Finally, the participants were asked to apply Mindmapping to a problem of their choice.

In contrast to Brainstorming and Mindmapping, which are currently used by designers (Gonçalves, Cardoso, \& Badke-Schaub, 2014), methods of the TD condition and particularly TRIZ are considered to be complex and thus to require much more time in order to be understood and successfully applied (e.g., Gundlach \& Ulbricht, 2006; llevbare, Probert, \& Phaal, 2013). Therefore, a dedicated training was designed in order to provide the participants with the most important concepts in a shorter timeframe. At the end of the training in the TD condition, the participants obtained a sheet which synthesized the problem-solving process according to these methodologies. All participants, in the TD as well as in the GT condition, were allowed to keep the printed training support for the following problem-solving sessions.

In order to foster methodological understanding and application, all groups where then asked to engage for two hours in an initial creative problem-solving task. They were told to follow a generic problemsolving meta-strategy consisting of problem definition; divergent idea generation; idea evaluation; convergent idea improvement; and solution generation. During this pedagogical case study, the participants had to generate propositions for the treatment of cancer using ionizing radiation without harming the patient's healthy tissue. This problem was derived from the so-called Duncker Radiation Problem (Duncker, 1945). During this case study, phases of autonomous work were followed by phases during which the participants were provided with 
possible results that had been obtained by the authors by application of the different methodological approaches.

\section{3 | Problem to solve}

After a short break, all participants had to engage the problem-solving task which was used for data collection. The task as well as the support provided to the participants is given in Table 1.

The problem was selected for the following reasons:

- The problem stems from a highly science and technology-based domain, that is, creativity and unorthodox approaches for problem solving are possible but must take into account complex causeand-effect relations.

- The initial and goal states are very ill-structured and a variety of problem analyses, problem statements, and solution strategies can be imagined, which classifies this problem as a design problem (Goel \& Pirolli, 1992; Jonassen, 2000). This makes the problem setting also open for engineering approaches and the application of engineering knowledge and know-how.

- However, the problem statement as well as the provided literature use codified language which is difficult to understand for problem solvers without a life science background, such as the engineering participants.

- There are existing solution propositions in the literature to which the participants' ideas can be compared.

In order to be able to prepare the task, the participants were provided with the problem description and the scientific literature some days before the problem-solving session.

\section{4 | Data collection and analysis}

Data collection was performed in three ways:

- After the pedagogical case study and the investigated problemsolving activity, the participants were asked to fill in a questionnaire on a seven-point Likert-type scale ranging from "not at all" to "completely". The questionnaire enquired into aspects like the participants' personal perception of the value of their knowledge with respect to the problem at hand (before the preparation of

TABLE 1 Problem-solving task to be engaged during the experiment

\begin{tabular}{ll} 
Scenario & $\begin{array}{l}\text { The problem solvers are members of a team in } \\
\text { the domain of medicine who have total freedom } \\
\text { to propose new research projects and all types } \\
\text { of treatment }\end{array}$ \\
\hline Problem & $\begin{array}{l}\text { Propose creative solutions to the problem of } \\
\text { opportunistic adenovirus infections of children } \\
\text { which are in an immunosuppressed state due to } \\
\text { hematopoietic stem cell transplantation }\end{array}$ \\
Fictional resources & $\begin{array}{l}\text { Sufficient financial, scientific, and technological } \\
\text { resources }\end{array}$ \\
Real resources & $\begin{array}{l}\text { Internet; scientific databases; scientific publications } \\
\text { in order to give an overview on the problem and } \\
\text { existing solution strategies }\end{array}$
\end{tabular}

TABLE 2 Questionnaire questions

\begin{tabular}{|c|c|}
\hline Code $^{a}$ & Question \\
\hline 2Q1 & $\begin{array}{l}\text { I have prepared the problem at hand (adenovirus } \\
\text { infection) (by reading the provided papers, } \\
\text { internet inquiry, etc.) before the treatment } \\
\text { of the problem. }\end{array}$ \\
\hline 1/2Q2 & $\begin{array}{l}\text { Before the preparation of the problem at hand, } \\
\text { I possessed a certain amount of knowledge } \\
\text { in the problem domain (adenovirus infection). }\end{array}$ \\
\hline $1 / 2 \mathrm{Q} 3$ & $\begin{array}{l}\text { My knowledge about the problem seemed } \\
\text { adequate for the treatment of the problem. }\end{array}$ \\
\hline $1 / 2 \mathrm{Q} 4$ & $\begin{array}{l}\text { I believe to have understood the content of } \\
\text { the training which preceded the case study. }\end{array}$ \\
\hline 1/2Q5 & $\begin{array}{l}\text { I was motivated to treat the problem (adenovirus } \\
\text { infection). }\end{array}$ \\
\hline 1/2Q6 & $\begin{array}{l}\text { The methods acquired during the training helped } \\
\text { me to better understand the problem. }\end{array}$ \\
\hline 1/2Q7 & $\begin{array}{l}\text { The methods acquired during the training helped } \\
\text { me during the generation of solutions. }\end{array}$ \\
\hline 1/2Q8 & $\begin{array}{l}\text { The methods acquired during the training helped } \\
\text { my group to better communicate. }\end{array}$ \\
\hline
\end{tabular}

${ }^{a}$ First digits of the code: 1 , question asked after the pedagogical case study; 2 , question asked after the investigated problem-solving task.

the problem and in general), perceived understanding of the methods taught during the training, personal motivation, and the value of the method for problem understanding, for problem solving and for communication (see Table 2).

- The participants were asked to document the results of each process step on dedicated sheets. In order not to privilege one of the two methodological approaches, i.e., the GT or TD condition, the sheets were designed following a generic creativity process (Merrifield, Guilford, \& Christensen, 1962). Initial reasoning and analysis of the problem was sought to be documented on "problem identification sheets" (PIS), problem statements and associated sub-problems were to be documented on "problem structuring sheets" (PSS), the results of the divergent idea generation processes should be filled into "concept sheets" (CS) and final solution propositions were sought to be noted in "solution sheets" (SS). In addition, the participants were asked to trace, whenever possible, links between the documentation sheets, e.g. to indicate what problem statement led to what concept and so on. In addition to this, the participants who had followed the TD training were required to note, whenever possible or applicable, the method or heuristic which led to a notation. For these indications, dedicated cases had previously been inserted into the sheets.

- The concepts (CS) and solutions (SS) generated by the participants were evaluated by two domain experts, i.e., by two experienced researchers in virology, on a seven-point Likert-type scale according to five independent creativity-related evaluation parameters (Dean, Hender, Rodgers, \& Santanen, 2006), which are given in Table 3.

The output of the experiment, i.e. the replies on the two questionnaires as well as the creativity ratings attributed to the concept (CS) and solution sheets (SS), were analysed using analysis of variance (ANOVA), and the calculation of correlation parameters. Figure 2 
TABLE 3 Creativity-related evaluation parameters for creative process output

\begin{tabular}{ll}
\hline Criterion & Explanation \\
\hline Feasibility (Acceptability) & $\begin{array}{l}\text { The degree to which the idea is socially, } \\
\text { legally, or politically acceptable and } \\
\text { technically feasible }\end{array}$ \\
\hline Pertinence (Applicability) & $\begin{array}{l}\text { The degree to which the idea applies to } \\
\text { the stated problem }\end{array}$ \\
Effectiveness & $\begin{array}{l}\text { The degree to which the idea will solve } \\
\text { the problem }\end{array}$ \\
$\begin{array}{l}\text { Depth (Implicational } \\
\text { explicitness and }\end{array}$ & $\begin{array}{l}\text { The degree to which there is a clear } \\
\text { relationship between the } \\
\text { recommended action and the expected } \\
\text { outcome; the breadth of coverage with } \\
\text { regard to who, what, where, when, why, } \\
\text { and how; hence the degree of detail to } \\
\text { which the idea is described }\end{array}$ \\
Originality & $\begin{array}{l}\text { The degree to which the idea is not only } \\
\text { rare but is also ingenious, imaginative, } \\
\text { or surprising (especially with regard to } \\
\text { already existing solutions) }\end{array}$ \\
\hline
\end{tabular}

provides an overview of the experimental protocol as well as on data collection and analysis.

\section{5 | RESULTS}

\section{1 | Descriptive results}

The 20 groups produced a total exploitable outcome of

- 83 problem identification sheets

- 62 problem structuring sheets

- 162 concept sheets

- 46 solution sheets of different types and degrees of detail. Figure 3 gives examples of concept and solution sheets.

The overall inter-rater reliability of the expert evaluation of the generated concepts and solution propositions amounts to a Cronbach's alpha of $a=0.728$, which is considered an acceptable value. Three concepts and one solution proposition could not be evaluated due to ambiguous or indistinct documentation. Hence, the number of concepts which entered the statistical analysis totals 159 and the number of solution propositions amounts to 45 .

The problem structuring sheets which had been generated by the groups in the TD condition were analysed and assigned to the TD tools which had been introduced during the training. The monodisciplinary teams of the LS condition used 3.5 TRIZ and USIT tools on average, whereas the multidisciplinary teams of the L2M condition used on average 5.4 tools. Moreover, two groups in the L2M conditions applied all proposed tools which were introduced during the training. In the LS condition, no group did so. Ideality (TRIZ) and the closed world method (USIT) were the most used concepts in the two conditions.

\subsection{Quantitative results}

In this section the relevant quantitative statistical results will be presented, focusing on significant and marginal effects. For all other parameters, no significant effect could be detected or the effect was not related to the hypotheses. For an overview of the relevant significant and marginal effects, please see Tables 4 and 5 .

\subsection{1 | Effects of disciplinary group composition and par- ticipant background}

Both the participants' disciplinary background and disciplinary group composition were found to be related to the participants' evaluation of their personally held knowledge. Individuals with a life science
General Creativity Methods
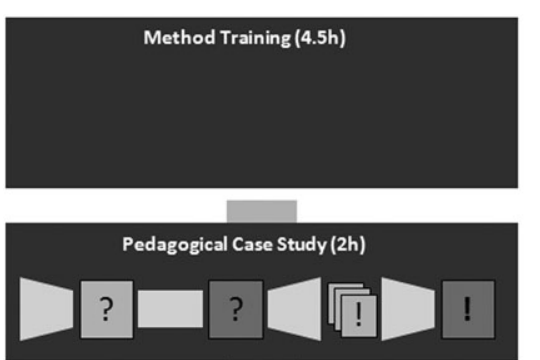

TRIZ and Derivatives

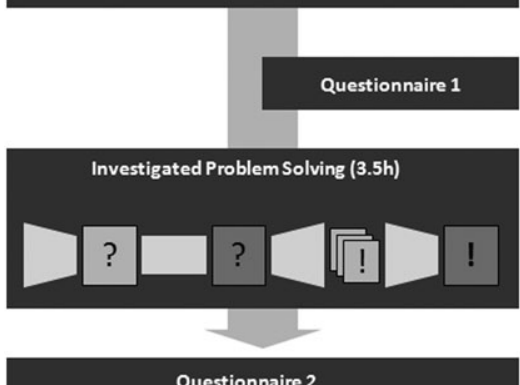

Questionnaire 2

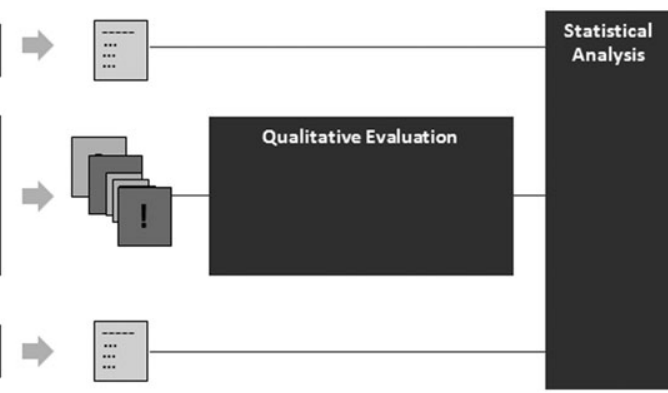

FIGURE 2 Experimental protocol, data collection, and data analysis 

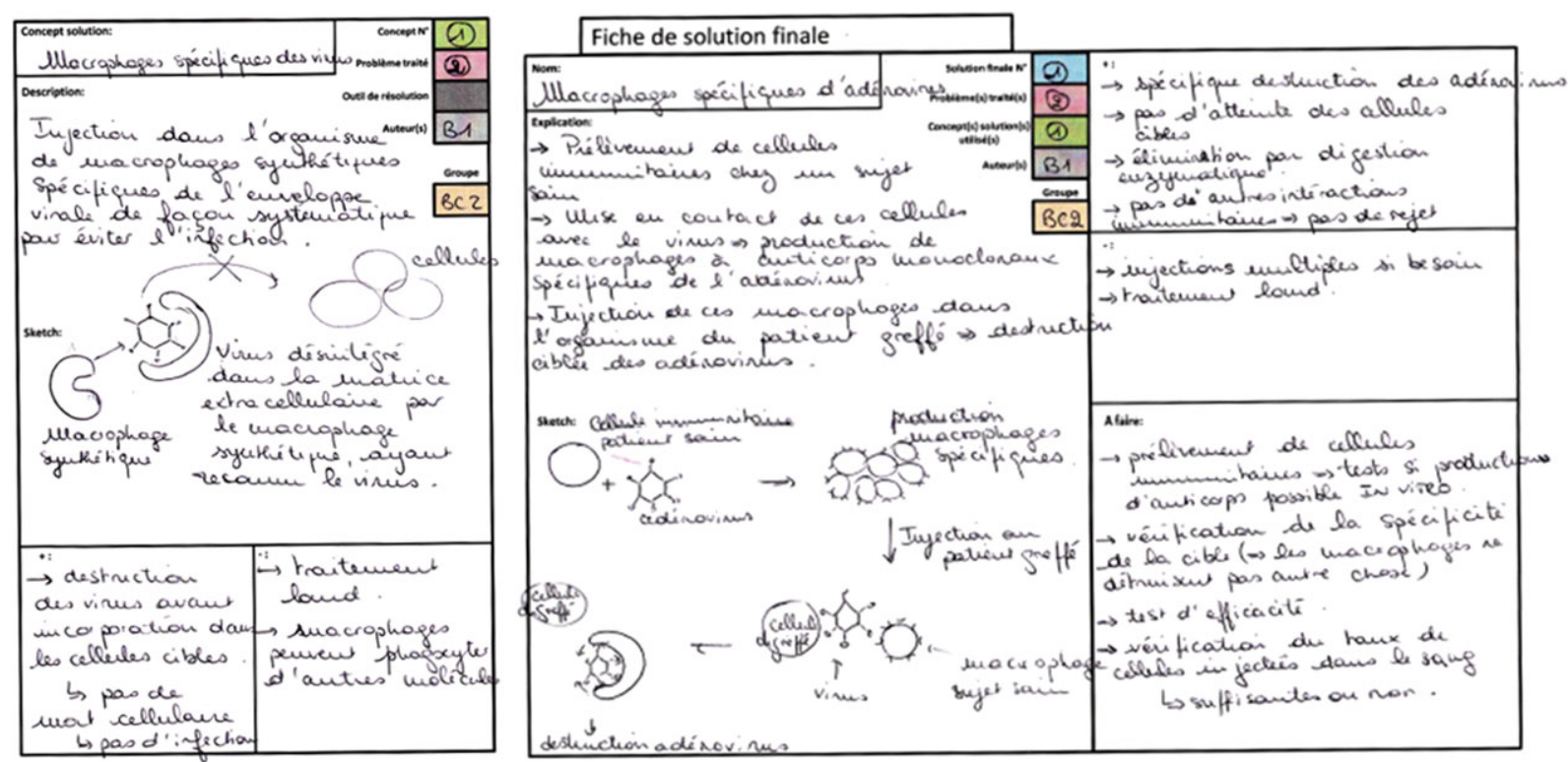

FIGURE 3 Examples of concept sheets (left) and solution sheets (right) generated during the experiment [Colour figure can be viewed at wileyonlinelibrary.com]

background reported more likely to make use of relevant problemrelated knowledge both before $(F(1 / 57)=62.53 ; p=0.001)$ and after $(F(1 / 57)=21.58 ; p=0.001)$ the preparation of the problem at hand. Moreover, disciplinary group composition seems to impact the evaluation of personally held knowledge (Figure 4). In monodisciplinary teams, the perceived value of the personally held knowledge of $\mathrm{ME}$ and LS participants with respect to the problem at hand was similar. However, in multidisciplinary teams, LS students tended to evaluate their knowledge to be more important than did ME participants ( $F(1 /$ 26 ) $3.26 ; p=0.084$ ). Also, multidisciplinary groups produced solution propositions that were documented in significantly more depth ( $F(1)$ $45)=4.42 ; p=0.042$ ) than the solution propositions produced by monodisciplinary teams. In a similar realm, differences in view of personally held knowledge with regard to the problem at hand were found to moderately impact the depth in which solution propositions were documented $(r(45)=0.383 ; p=0.009)$.

\subsection{2 | Effects of methodological support}

First of all, the type of methodological support seems to impact the participants' evaluation of their personally held knowledge with respect to the problem at hand. Individuals in the GT condition tended to report having possessed more relevant knowledge than did participants in the TD condition $(F(1 / 57)=3.67 ; p=0.061)$. Second, the perceived methodological support for understanding the problem was evaluated to be significantly different. The participants in the TD condition evaluated their method significantly better compared to participants in the GT condition $(F(1 / 54)=4.7 ; p=0.035)$. Taking into account the quantity of identified sub-problems and of generated problem models, the following was detected. The teams in the GT condition identified more sub-problems $(F(1 / 18)=10.0 ; p=0.005)$ but generated fewer problem models $(F(1 / 18)=22.62 ; p=0.001)$ than did the groups in the TD condition. Regarding the creativity-related attributes of the process outcome, only the degree to which the products were described in detail (Depth) was impacted by the methodological support. The initial ideas generated by the groups in the GT condition were evaluated to be documented in more depth than the ideas in the TD condition $(F(1 / 59)=11.77 ; p=0.001)$. The calculation of correlation parameters yielded the following results. In the GT condition, the degree to which the participants had prepared the problem to solve (e.g., reading the provided literature) was positively correlated to the participants' perception of method value for problem understanding $(r(79)=0.304 ; p=0.006)$, problem solving $(r(79)=$ 0.424; $p=0.001)$, and intra-group communication $(r(79)=0.530 ; p=$ 0.001). In the TD condition, the correlations were either less strong or non-existent $(r(72)=0.228 ; p=0.054 ; r(72)=0.040 ; p=0.738$; $r(72)=0.332 ; p=0.004)$. Finally, a strong positive correlation of differences with respect to problem-related knowledge among the members of a group and the perceived value of methods in the GT condition for intra-group communication was detected. The correlation was found to be strong for both problem-related knowledge before the preparation of the problem to solve $(r(79)=0.435 ; p=0.001)$ and in general $(r(79)=0.453 ; p=0.001)$. For TRIZ and USIT, both correlations were negative $(r(72)=-0.295 ; p=0.012 ; r(72)=-0.339 ; p=0.004)$.

\subsection{3 | Combined effects of disciplinary group composition and methodological support}

Finally, several results relate to a combined effect of disciplinary group composition or participant background and the chosen methodological support. First, after the initial case study, among the participants in the TD condition, the participants of monodisciplinary groups judged the value of the methodological support for problem understanding higher than did participants in monodisciplinary teams $(F(1 / 26)=14.3 ; p=$ 0.001). Furthermore, with regard to the creativity-related evaluation of the creative outcome, one significant combined effect was detected. With regard to the criterion Originality, the value of the methodological support-Brainstorming and Mindmapping or TRIZ and USITdepends on disciplinary group composition. Whereas monodisciplinary 


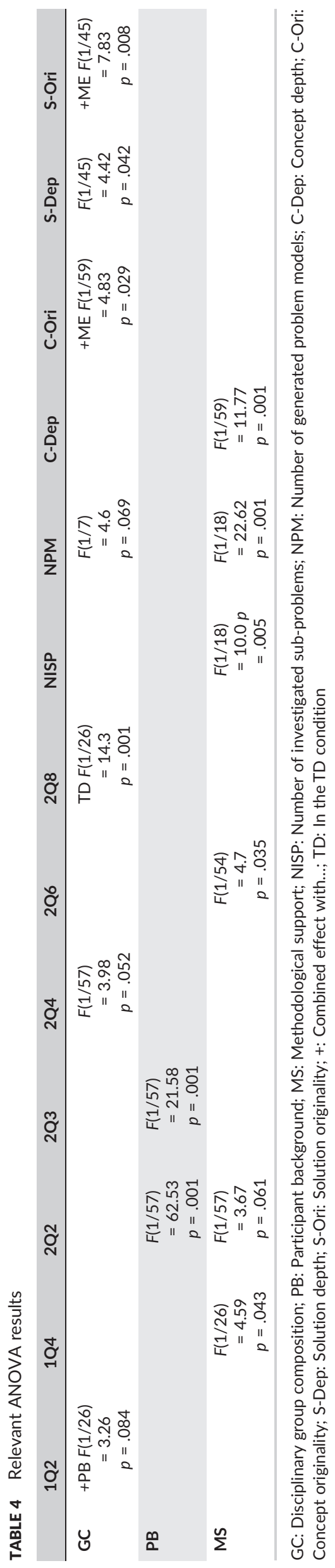

TABLE 5 Relevant results of the calculation of correlation parameters

\begin{tabular}{|c|c|c|c|c|}
\hline & 2Q6 & 2Q7 & 2Q8 & S-Dep \\
\hline 2Q1 & $\begin{array}{l}\mathrm{GT} \\
r=.304 ; \\
\quad p=.006 \\
\text { TD } \\
r=228 ; \\
\quad p=.054\end{array}$ & $\begin{array}{l}\text { GT } \\
r=.424 ; \\
\quad p=.001 \\
\text { TD } \\
r=.040 ; \\
p=.738\end{array}$ & $\begin{array}{l}\mathrm{GT} \\
r=.530 ; \\
p=.001 \\
\mathrm{TD} \\
r=.332 ; \\
p=.004\end{array}$ & \\
\hline 2Q2-E & & & $\begin{array}{l}\text { GT } \\
\begin{aligned} r=.435 ; \\
p=.001 \\
\text { TD-E } \\
r=-.295 ; \\
p=.012\end{aligned}\end{array}$ & $\begin{array}{c}r=.383 ; \\
p=.009\end{array}$ \\
\hline Q3-E & & & $\begin{array}{l}\text { GT } \\
r=.453 ; \\
p=.001 \\
\text { TD } \\
r=-.339 ; \\
p=.004\end{array}$ & \\
\hline
\end{tabular}

E: Standard error of answers to question; GT: In the GT condition; TD: In the TD condition

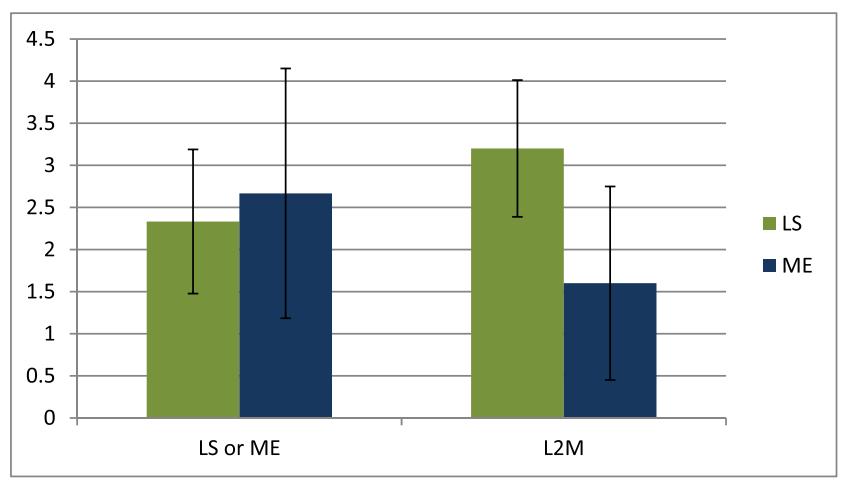

FIGURE 4 Combined effect of disciplinary group composition and participant background on perceived value of personally held knowledge [Colour figure can be viewed at wileyonlinelibrary.com]

teams generated more original concepts $(F(1 / 59)=4.83 ; p=0.029)$ and solution propositions $(F(1 / 45)=7.83 ; p=0.008)$ (Figure 5$)$ in the GT condition, the opposite was true for multidisciplinary groups using TRIZ and USIT. Finally, both the participants' disciplinary background and disciplinary group composition seem to impact the understanding and application of methodological concepts. After the initial case study, among the participants in the TD condition, those with a mechanical engineering background reported more likely to have understood the methodological training content than did participants with a life science background $(F(1 / 26)=4.59 ; p=0.043)$. After the investigated second case study, among the participants in both methodological conditions, members of multidisciplinary teams evaluated personal method understanding slightly better $(F 1 / 57)=3.98 ; p=$ 0.052 ) than did members of monodisciplinary teams. Finally, the analysis of the problem structuring sheets generated in the TD condition revealed that multidisciplinary groups tend to use tools of TRIZ and USIT more often than do monodisciplinary teams $(F(1 / 7)=4.60 ; p=$ 0.069). 


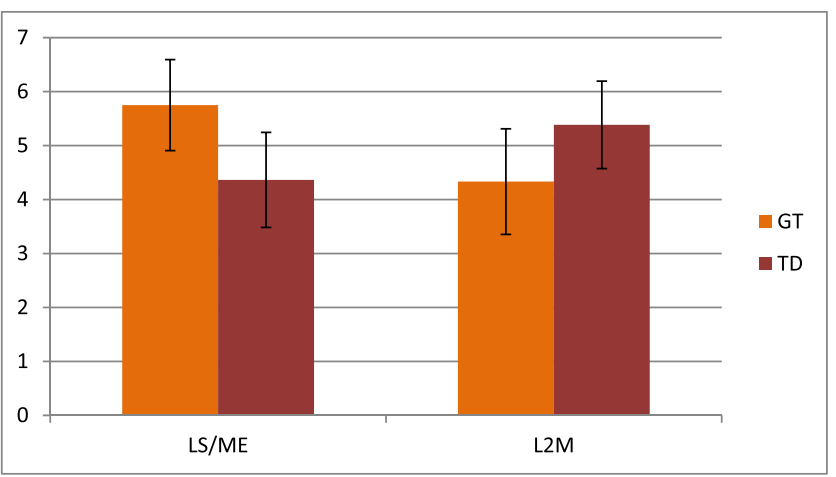

FIGURE 5 Impact of methodological support on originality of generated solutions depending on disciplinary group composition [Colour figure can be viewed at wileyonlinelibrary.com]

\section{6 | DISCUSSION}

The results presented in the previous section allow a differentiated insight on the impact of disciplinary group composition and methodological support on the process of creative problem solving by groups in knowledge and technology-intensive domains.

\section{1 | Discussion of results with respect to Hypothesis 1}

Hypothesis 1 relates to the impact of heterogeneity in terms of disciplinary group composition on the creative problem-solving process in groups, its outcome and information processing during this process.

Hypothesis 1a suggests an impact of disciplinary group composition on the process of creative group problem solving. The increased depth of the solutions produced by the multidisciplinary (L2M) teams compared to monodisciplinary groups (LS/ME) is considered indirect evidence in favour of that hypothesis. Two explanations for that result can be offered. First, multidisciplinary group composition is likely to add several types of conflicts to group processes (Gebert et al., 2006; Van Knippenberg \& Schippers, 2007). Especially value conflicts, which relate to the desired outcome (Gebert et al., 2006), and task conflicts, which describe disagreements with regard to problem solving strategies (Pelled et al., 1999), can be the result of disciplinary diversity. Those conflicts, under certain conditions, have been found to improve the consideration of previously unshared knowledge within a group (Brodbeck, Kerschreiter, Mojzisch, Frey, \& Schulz-Hardt, 2002). The integration of that knowledge during the discussion of a solution proposition is likely to improve the degree to which the solution is documented. A second, probably more trivial, explanation would be that the presence of team members with a different disciplinary background forces the others to describe their ideas in more detail. Once those explanations are given, they are also reflected in the documentation of the results.

The combined impact of disciplinary group composition and disciplinary background on the participants' evaluation of personally held knowledge is more directly related to Hypothesis 1a. One can argue that knowledge which is considered not valuable with respect to a problem by the knowledge owner has a higher risk of remaining unshared. Likewise, the excessive consideration of knowledge that is estimated to be superior by the majority of the group members risks dominating group problem-solving processes. In that sense, the result confirms the view of Nemeth et al. (Nemeth, 1986; Nemeth \& Nemeth-Brown, 2003), who argue that majority influence in groups leads to convergent thinking in both majority and minority individuals. Hence, it provides evidence, albeit marginal, for the impact of disciplinary group composition on information sharing and thus information processing in groups. The fact that the result could not be reproduced after the investigated second case study can be explained by a learning effect among the participants. The experience that non-domain knowledge, which was considered by some $a$ priori not relevant to the problem, can contribute to interesting results of problem-solving processes could have led to a re-evaluation of that knowledge with respect to the second problem by both ME and LS students. Hence, the more equal estimation of personally held knowledge with respect to the second problem can be interpreted as an indicator that exemplary case studies can help to reduce problems related to knowledge transfer in working groups (Kane et al., 2005).

Hypothesis $1 \mathrm{~b}$ relates to the impact of disciplinary group composition on quantitative and qualitative aspects of the generated concepts and solution propositions. The finding that solutions generated by interdisciplinary L2M groups are described in more detail than the solutions produced by monodisciplinary LS and ME groups can be directly associated to that sub-hypothesis. In addition, the positive correlation between differences regarding the perceived value of personal knowledge among members of a group and the degree of detail to which solution propositions are described also confirms that hypothesis. Together, these results suggest that, due to individual differences in terms of possessed knowledge, multidisciplinary groups generate more deeply reflected creative outcomes than do monodisciplinary groups.

\subsection{Discussion of results with respect to Hypothesis 2}

Hypothesis 2 states an impact of the methodological support on the creative problem-solving process in groups, its outcome and information processing during this process.

Hypothesis 2a, which suggests that the choice of the method used during the problem-solving process impacts the latter, was supported. The fact that the participants in the TD condition evaluated the methodological support to be significantly more useful when it comes to problem understanding obviously exerts influence on the problemsolving process. The result experimentally confirms llevbare et al.'s (2013) empirical finding that the use of TRIZ leads to improved problem analysis in teams. Further, methodological impact is somewhat confirmed by the difference in the number of sub-problems and problem models that were identified and respectively generated in the two methodological conditions. Whereas the groups in the GT condition identified significantly more sub-problems, the teams in the TD condition produced significantly more problem structuring sheets. One possible interpretation of these results is that the value of TD for problem structuring and problem modelling, which translates into an increased number of problem models, also leads to more focused problem identification in TD groups. At the same time, due to a lack of 
methodological support for problem analysis and problem understanding, GT groups engage in a more extensive and divergent problem identification process. Those results are interesting if one takes into account the findings of Fricke (1996), who suggests that "balanced" strategies, which are characterized by reasonable expansion of the search space, are most likely to help designers to find quality solutions in limited timeframes. On the assumption of an extrapolation of Fricke's findings to group processes, the present findings suggest that the choice of the methodological support can help teams to adjust their meta-strategies for problem solving. In initial problem-solving phases, TRIZ and derived approaches seem to lead to a restriction of the problem space. In subsequent phases of deeper problem analysis, those approaches allow an enlargement of the search space compared to intuitive methods.

In addition, the measured correlations between the participants' evaluation of personally held knowledge and method value for problem understanding and group communication are of interest here. They provide some insight into the influence of methodology on group information processing during group problem solving. The results suggest that GT methods-Brainstorming and Mindmapping-are more suitable to foster the processing of recently acquired information within groups. Probably most important in view of interdisciplinary group problem solving are the significant differences between the methodological approaches regarding the support of group communication when perceived knowledge differences among the team members are high. Whereas the capacity of methods of the GT condition to foster group communication is strongly positively related to perceived differences in terms of expertise in groups, the correlation is moderately negative in the TD condition. These results reflect only the subjective perception of the participants and somewhat contrast other findings (see below). However, they point towards some potential drawbacks of TRIZ and USIT in respect to the facilitation of problem solving in interdisciplinary teams. Together with other results presented here, those findings may provide help for the choice of methodological support for the facilitation of group problem solving processes. Logical creativity-enhancing methodology, compared to intuitive methods, seems to have overall advantages in terms of support for problem understanding. Perhaps more obviously, when it comes to the facilitation of solution generation, the methodological support of both approaches seems to decrease with increased problem-related knowledge. That means that domain novices are more likely than experts to require methodological support for the generation of solution propositions to a given knowledge-intensive problem. Furthermore, independently from general domain knowledge, Brainstorming and Mindmapping should be used only when team members have well prepared the problem to be solved, whereas the support of TRIZ and derived methods does not depend on such constraints.

The fact that participants in the TD condition, before the preparation of the problem, considered their knowledge with respect to the problem domain as sparser than did participants trained in the GT condition, can also be interpreted against an information processing background. One can argue that the use of methodology of the TD condition leads to the identification of aspects of the problem setting, of which the participants did not possess any knowledge, which, in turn, impacts the value perception of their knowledge. However, it should be noted that the discussed statistical effect is only marginal and that the explanation given here should be tested elsewhere.

An impact of the methodological support on quantitative aspects of the generated concepts and solutions was stated in Hypothesis $2 b$. That hypothesis could not be validated based on the experimental findings. For the majority of the creativity-related evaluation parameters outlined in Table 3, no significant relationship between method and outcome could be found. In this sense, the present experiment confirms the findings of Chulvi et al. (2013), who could not detect significant differences in terms of usefulness between ideas that had been generated using TRIZ and those developed using intuitive creativity methods. The only experimental outcome that can be clearly related to Hypothesis $2 \mathrm{~b}$ points to a significant positive relationship between the use of GT methods and the depth of generated concepts. One possible explanation for this phenomenon could be that participants of the GT condition stated they possessed more problem-relevant knowledge prior to the experimental procedure.

\section{3 | Discussion of results with respect to Hypothesis 3}

Hypothesis 3 suggests a mediating effect of disciplinary group composition regarding the impact of methodological support on the process $(\mathrm{H} 3 \mathrm{a})$ of creative problem solving in groups and its outcome $(\mathrm{H} 3 \mathrm{~b})$.

With regard to Hypothesis $3 a$, not enough results supporting this hypothesis could be found in the replies to the questionnaires and from the evaluation of the creative output of the problem-solving groups. Either the results were of only marginal significance ( $p=$ 0.052; $p=0.069$ ) or an effect was detected only after the initial case study and disappeared after the investigated one.

Concerning Hypothesis $3 \mathrm{~b}$, the link between disciplinary group composition, methodological support, and creative output originality is important. As mentioned previously, application of GT and TD exerts a significant influence on the originality of both generated concepts and solutions depending on whether the composition of the group is monodisciplinary (LS) or multidisciplinary (L2M). Whereas GT is advantageous when used by LS teams, the opposite is true for L2M groups. Those findings are interesting for two main reasons. First, originality is considered one of the most important evaluation criteria for the output of creative problem-solving processes. Second, among the criteria introduced here, originality probably indicates best the extent to which new knowledge is applied in the generated creative products. In order to further investigate the combined impact of disciplinary group composition and methodological support on the type of generated output and the knowledge applied in the latter, a detailed qualitative analysis of that output would be necessary.

\section{4 | Summary of results}

The present experiment was designed to test three hypotheses. The first hypothesis suggested an impact of disciplinary group composition on the process of creative problem solving in groups in knowledgeintensive domains as well as on the output of that process. The increased depth with which multidisciplinary groups describe their solution propositions provides support for both aspects of the 
hypothesis. Hence both aspects of Hypothesis 1 obtain some support. The polarizing impact of interdisciplinarity in groups on the-subjective -evaluation of personally held knowledge also point to the validation of a disciplinary impact on information processing during group problem solving. The reason is that potentially valuable extra-domain knowledge that is not shared-or sufficiently defended-due to a potential underestimation has no chance of being applied for problem solving.

The second hypothesis, analogously to the first, suggested an impact of the methodological support on the creative problem-solving process in groups and on its creative outcome. The analysis of the documentation of the problem-solving process and the evaluation of the participants' replies to the questionnaires confirm a method impact on the problem-solving process. Intuitive approaches seem to lead to broader definitions of sub-problems whereas analytical methodology stimulates more in-depth problem analysis. Furthermore, TRIZ and USIT, compared to Brainstorming and Mindmapping, feature an increased value for problem understanding. That value, contrary to that of intuitive approaches, does not depend on the participants' preparation of the problem at hand. However, the impact of the chosen methodological approach on the creative quality of the generated concepts and solutions could not be validated. Hypothesis 2 is thus only partially validated by the present experiment.

The third hypothesis relates to a mediating effect between disciplinary group composition and methodological support in terms of the problem-solving process in groups and its outcome. At least in terms of originality of the generated output, there seems to be a mediating effect between disciplinary group composition and methodological support. Whereas intuitive methods seem to be advantageous in monodisciplinary groups, the opposite is true for multidisciplinary teams. Hence, whereas Hypothesis 3a does not receive any support, Hypothesis $3 \mathrm{~b}$ is supported by the experiment.

\section{5 | Limitations}

In the present experiment, a focus was put on quantitative data collection and analysis. That research strategy implies a certain number of qualitative limitations. First of all, students and not professional researchers or engineers were taken as participants. However, the domain experts in charge of evaluating the generated concepts certified a high quality and state-of-the-art output of the problem-solving session. Moreover, the detected differences regarding perceived value of personal knowledge between the "expert" and "non-expert" participants were significant. Thus, we believe that the generated experimental conditions reflect well the professional reality.

Second, both training time and the time that the participants were given to solve such a complex problem were very short. The time necessary to learn and successfully apply complex approaches like TRIZ is considered at least one order of magnitude higher. Taking into account the complexity of both this method and the problem to solve, there is a risk that the participants in the TD condition spent too much time and effort in understanding and correctly apply the methodological tools, thereby losing time for solution generation. Or the problem solvers simply did not have enough time for a proper application of TD models which could bias the evaluated creative performance of the TRIZ tools.
A means to counter this problem would be real-time data by video- or audio-recording and a subsequent analysis of the time spent for either method and problem-related activities.

This being said, it should be stressed that the conditions under which the participants were expected to apply the respective methods correspond-according to the authors' experience-well to the constraints of real-life industrial workshops and for interdisciplinary and inter-institutional workshops.

Finally, it could be argued that having chosen mechanical engineering as one of the disciplinary backgrounds of the participants could perhaps skew the general applicability of the results to interdisciplinary problem solving irrespective of the participating disciplines. Even though the participants with ME background reported not to have had any experience in this regard, the fact that TRIZ and USIT were developed in mechanical engineering could have given them a certain advantage over the life science students. However, a better understanding of the training content by ME participants could only be detected after the initial case study. Therefore, we consider the methodological advantage of the participants with an ME background during the investigated case study to be negligible.

\section{6 | Implications}

The results presented in this paper have managerial, theoretical as well as pedagogical implications.

From a management perspective, the findings indicate that the choice of the methodology to support creative problem solving in groups in knowledge-intensive and high-technology domains should depend on several aspects. Disciplinary group composition, perceived average problem-related expert knowledge as well as differences with respect to that knowledge within a multidisciplinary group are important factors to take into account. Moreover, the application of intuitive deliberate creativity methods on the one hand and more logical analytical methods on the other can effectively influence a group's metastrategy (Fricke, 1996) for problem solving. Even though it must be confirmed by further research, the finding that disciplinary group composition influences the participants' evaluation of personally held knowledge, also bears important implications for knowledge management in organizations. The processing and the integration of extradomain knowledge into a given domain-specific problem setting require support. That support can be in the form of quantitative adjustments of the group composition in order to profit from majority/ minority influence (Brodbeck et al., 2002; Nemeth \& Nemeth-Brown, 2003) effects. It might also be possible to favour the integration of extra-domain knowledge by combining approaches presented here with progressive methods (Shah et al., 2000). Gallery Method (Van Gundy, 1988) or Method 635 (Rohrbach, 1969) are techniques which allow every participant to provide her/his contribution without group pressure. Finally, against the background of an ever-increasing application of Open Innovation processes and structures, the differences with regard to the creative outcome as a combined effect of group composition and methodological support seem important. Based on these findings one can argue for an increased use of problem structuring and problem modelling methods of TRIZ and USIT when problems 
are shared with extra-domain problem solvers, be it in the case of Innovation Networks or collaborative workshops of any sort.

With regard to theoretical aspects of problem solving, the following implications were identified. First, disciplinary diversity in problem-solving groups promotes the detailed description of solution propositions. We argue that this increased degree of detail points towards an increased discussion of ideas during the problem-solving process. Second, from the evaluation of the questionnaires, it seems at first sight that the value of logical analytical approaches is higher for problem identification and problem analysis than it is for the generation of solution propositions. Whether this result is due to the fact that problem-solving heuristics only indirectly lead to the generation of ideas-as reported elsewhere (Howard, Culley, \& Dekoninck, 2011)-could not be tested with the current research methodology. A confirmation of these findings and-to some degree-a response to open questions like the impact of group composition and methodological support on the development of ideas and solutions as well as on the type of generated creative outcome requires more qualitative approaches. Such approaches could, for example, use audio- and video-recording for the analysis of the problem-solving groups in order to map the dynamics of problem statements and ideas during the problem-solving process. In a similar realm, a more thorough documentation of the generated concepts and solutions and finally a mapping of these onto a "knowledge map" of some sort could provide interesting insight into the question of how to integrate knowledge from specific domains into the creative problem-solving process.

Finally, the experimental results indicate a sound use of TRIZ and USIT tools by the participants. From a pedagogical perspective, these findings are interesting insofar as they point to the potential of these methods to improve creative thinking in teams even after a short period of training.

\section{REFERENCES}

Altshuller, G. (1996). And Suddenly the Inventor Appeared: Triz, the Theory of Inventive Problem Solving. Worcester, MA: Technical Innovation Center.

Alves, J., Marques, M., Saur, I., \& Marques, P. (2007). Creativity and innova-

tion through multidisciplinary and multisectoral cooperation. Creativity and Innovation Management, 16, 27-34.

Baron, R. (1991). Positive effects of conflict: A cognitive perspective. Employee Responsibilities and Rights Journal, 4, 25-36.

Batzias, F., \& Siontorou, C. (2012). Creating a specific domain ontology for supporting R\&D in the science-based sector-The case of biosensors. Expert Systems with Applications, 39, 9994-10015.

Berry, D., \& Broadbent, D. (1987). The combination of explicit and implicit learning processes in task control. Psychological Research, 49, 7-15.

Brodbeck, F., Kerschreiter, R., Mojzisch, A., Frey, D., \& Schulz-Hardt, S. (2002). The dissemination of critical, unshared information in decision-making groups: The effects of pre-discussion dissent. European Journal of Social Psychology, 32, 35-56.

Buzan, T. (1984). Use your head. London: Guild Publishing.

Chan, J., Dow, S., \& Schunn, C. (2015). Do the best design ideas (really) come from conceptually distant sources of inspiration? Design Studies, $36,31-58$.
Chesbrough, H. (2003). The era of open innovation. MIT Sloan Management Review, 44, 35-41.

Chulvi, V., Gonzalez-Cruz, M., Mulet, E., \& Aguilar-Zambrano, J. (2013). Influence of type of idea-generation method on the creativity of solutions. Research in Engineering Design, 24, 33-41.

Clark, K., \& Fujimoto, T. (1987). Overlapping problem solving in product development. Cambridge, MA: Harvard Business School Press.

Cohen, W., \& Levinthal, D. (1990). Absorptive capacity: A new perspective on learning and innovation. Administrative Science Quaterly, 35, 128-152.

Cross, N. (2008). Engineering design methods: Strategies for product design. Chichester, UK: John Wiley \& Sons.

Cross, N., \& Clayburn Cross, A. (1995). Observations of teamwork and social processes in design. Design Studies, 16, 143-170.

De Dreu, C., De Vries, N., \& Weingart, L. (2003). Task versus relationship conflict, team performance, and team member satisfaction: A metaanalysis. Journal of Applied Psychology, 88, 741-749.

Dean, D., Hender, J., Rodgers, T., \& Santanen, E. (2006). Identifying quality, novel, and creative ideas: Constructs and scales for idea evaluation. Journal of the Association for Information Systems, 7, 646-698.

Dong, A., Kleinsmann, M., \& Deken, F. (2013). Investigating design cognition in the construction and enactment of team mental models. Design Studies, 34, 1-33.

Dougherty, D. (1992). Interpretive barriers to successful product innovation in large firms. Organization Science, 3, 179-202.

Duncker, K. (1945). On problem solving (Psychological Monographs 58). Washington, DC: American Psychological Association.

Erden, M., Komoto, H., Van Beek, T., D'Amelio, V., Echavarria, E., \& Tomiyama, T. (2008). A review of function modeling: Approaches and applications. Artificial Intelligence for Engineering Design, Analysis and Manufacturing, 22, 147-169.

Fayemi, P.-E., Maranzana, N., Aoussat, A., \& Bersano, G. (2014). Bioinspired design characterisation and its links with problem solving tools. Paper presented at the International Design Conference-DESIGN 2014, Dubrovnik.

Field, T. (1971). Some dimensions of a science cognitive style and their and their relevance for the classroom. Research in Science Education, 1, 19-27.

Finke, R., Ward, T., \& Smith, S. (1992). Creative cognition: Theory, research, and applications. Cambridge, MA: MIT Press.

Fleck, L. (1979). Genesis and development of a scientific fact. Chicago, IL: University of Chicago Press.

Fricke, G. (1996). Successful individual approaches in engineering design. Research in Engineering Design, 8, 151-165.

Gebert, D., Boerner, S., \& Kearney, E. (2006). Cross-functionality and innovation in new product development teams: A dilemmatic structure and its consequences for the management of diversity. European Journal of Work and Organizational Psychology, 15, 431-458.

Gericke, K., \& Blessing, L. (2011). Comparisons of design methodologies and process models across disciplines: A literature review. Paper presented at the International Conference on Engineering Design-ICED 11, Denmark.

Goel, V., \& Pirolli, P. (1992). The structure of design problem spaces. Cognitive Science, 16, 395-429.

Gonçalves, M., Cardoso, C., \& Badke-Schaub, P. (2014). What inspires designers? Preferences on inspirational approaches during idea generation. Design Studies, 35, 29-53.

Gruenfeld, D., Mannix, E., Williams, K., \& Neale, M. (1996). Group composition and decision making: How member familiarity and information distribution affect process and performance. Organizational Behavior and Human Decision Processes, 67, 1-15.

Gundlach, C., \& Ulbricht, R. (2006). Der Stellenwert der TRIZ-Methodik. In C. Gundlach, \& H. Nähler (Eds.), Innovation mit TRIZ: Konzepte, Werkzeuge, Praxisanwendungen. Düsseldorf: Symposion Publishing. 
Hinsz, V., Tindale, S., \& Vollrath, D. (1997). The emerging conceptualization of groups as information processors. Psychological Bulletin, 121, 43-64.

Horowitz, R. (1999). Creative problem solving in engineering design ( $\mathrm{PhD}$ thesis). Tel-Aviv University.

Howard, T., Culley, S., \& Dekoninck, R. (2011). Reuse of ideas and concepts for creative stimuli in engineering design. Journal of Engineering Design, $22,565-581$.

llevbare, I., Probert, D., \& Phaal, R. (2013). A review of TRIZ, and its benefits and challenges in practice. Technovation, 33, 30-37.

Jackson, S., May, K., \& Whitney, K. (1995). Understanding the dynamics of diversity in decision-making teams. In R. Guzzo, \& E. Salas (Eds.), Team effectiveness and decision making in organizations. San Francisco, CA: Jossey-Bass.

Jehn, K. (1997). A qualitative analysis of conflict types and dimensions in organizational groups. Administrative Science Quarterly, 42, 530-557.

Jehn, K., Northcraft, G., \& Neale, M. (1999). Why differences make a difference: A field study of diversity, conflict, and performance in workgroups. Administrative Science Quarterly, 44, 741-763.

Jonassen, D. (2000). Toward a design theory of problem solving. Educational Technology Research and Development, 48, 63-85.

Kane, A., Argote, L., \& Levine, J. (2005). Knowledge transfer between groups via personnel rotation: Effects of social identity and knowledge quality. Organizational Behavior and Human Decision Processes, 96, 56-71.

Koestler, A. (1964). The act of creation. London, UK: Hutchinson.

Kokotovich, V. (2008). Problem analysis and thinking tools: An empirical study of non-hierarchical mind mapping. Design Studies, 29, 49-69.

Lawson, B. (1979). Cognitive strategies in architectural design. Ergonomics, 22, 59-68.

Marais, S. (2010). The definition and development of Open Innovation models to assist the innovation process ( $\mathrm{PhD}$ thesis). University of Stellenbosch.

Mason, R. (1969). A dialectical approach to strategic planning. Management Science, 15, B-403-B-414.

Mathieu, J., Heffner, T., Goodwin, G., Salas, E., \& Cannon-Bowers, J. (2000). The influence of shared mental models on team process and performance. Journal of Applied Psychology, 85, 273-283.

Merrifield, P., Guilford, J., \& Christensen, P. (1962). The role of intellectual factors in problem solving. Psychological Monographs, 76, 1-21.

Milliken, F., \& Martins, L. (1996). Searching for common threads: Understanding the multiple effects of diversity in organizational groups. Academy of Management Review, 21, 402-433.

Mumford, M., Feldman, J., Hein, M., \& Nagao, D. (2001). Tradeoffs between ideas and structure: Individual versus group performance in creative problem solving. Journal of Creative Behavior, 35, 1-23.

Nemeth, C. (1986). Differential contributions of majority and minority influence. Psychological Review, 43, 23-32.

Nemeth, C., Brown, K., \& Rogers, J. (2001). Devil's advocate versus authentic dissent: Stimulating quantity and quality. European Journal of Social Psychology, 31, 707-720.

Nemeth, C., \& Nemeth-Brown, B. (2003). Better than individuals?: The potential benefits of dissent and diversity for group creativity. In P. Paulus, \& B. Nijstad (Eds.), Group creativity: Innovation through collaobration. Oxford, UK: Oxford University Press.

Olson, K., Walsh, M., Garg, P., Steel, A., Mehta, S., Data, S., ... Bangsberg, D. (2017). Health hackathons: Theatre or substance? A survey assessment of outcomes from healthcare-focused hackathons in three countries. BMJ Innovations. https://doi.org/10.1136/bmjinnov-2016-000147.

Osborn, A. (2009). Unlocking your creative power: How to use your imagination to brighten life, to get ahead. Lanham: Hamilton Books.

Pelled, L., Eisenhardt, K., \& Xin, K. (1999). Exploring the black box: An analysis of work group diversity, conflict, and performance. Administrative Science Quarterly, 44, 1-28.
Qureshi, A., Gericke, K., \& Blessing, L. (2013). Design process commonalities in trans-disciplinary design. Paper presented at the International Conference on Engineering Design 2013, Seoul.

Rohrbach, B. (1969). Kreativ nach Regeln-Methode 635, eine neue Technik zum Lösen von Problemen. Absatzwirtschaft, 12, 73-75.

Rothenberg, A. (1983). Psychopathology and creative cognition: A comparison of hospitalized patients, Nobel laureates and controls. Archives of General Psychiatry, 40, 937-942.

Rothenberg, A. (1987). Einstein, Bohr, and creative thinking in science. History of Science, 25, 147-166.

Rouse, W., \& Morris, N. (1985). On looking into the black box: Prospects and limits in the search for mental models. School of Industrial and Systems Engineering, Georgia Institute of Technology.

Schulz-Hardt, S., Jochims, M., \& Frey, D. (2002). Productive conflict in group decision making: Genuine and contrived dissent as strategies to counteract biased information seeking. Organizational Behavior and Human Decision Processes, 88, 563-586.

Schwenk, C. (1990). Effects of devil's advocacy and dialectical inquiry on decision making: A meta-analysis. Organizational Behavior and Human Decision Processes, 47, 161-176.

Schwenk, C., \& Valacich, J. (1994). Effects of devil's advocacy and dialectical inquiry on individuals versus groups. Organizational Behavior and Human Decision Processes, 59, 210-222.

Shah, J., Kulkarni, S., \& Vargas-Hernandez, N. (2000). Evaluation of idea generation methods for conceptual design: Effectiveness metrics and design of experiments. Journal of Mechanical Design, 122, 377-384.

Sickafus, E. (1997). Unified structured inventive thinking: How to invent. Grosse lle: Ntelleck.

Tjosvold, D., Meredith, L., \& Wong, C. (1998). Coordination to market technology: The contribution of cooperative goals and interaction. The Journal of High Technology Management Research, 9, 1-15.

Tomiyama, T. (2006). Dealing with complexity in design: A knowledge point of view. Design Methods for Practice, 137-146.

Van Gundy, A. (1988). Techniques of structured problem solving. New York, NY: Van Nostrand Reinhold.

Van Knippenberg, D., \& Schippers, M. (2007). Work group diversity. Annual Review of Psychology, 58, 515-541.

Yoshioka, M., Umeda, Y., Takeda, H., Shimomura, Y., Nomaguchi, Y., \& Tomiyama, T. (2004). Physical concept ontology for the knowledge intensive engineering framework. Advanced Engineering Informatics, 18, 95-113.

Malte Schöfer, during his time at LCPI and AIM, was consultant in innovation management and systems engineer. During his PhD research he was interested in the potential of problem-solving methodology for the improvement of interdisciplinary creativity and technology transfer in NPD processes. He is currently working as Project Manager for railway and automotive industry at P3 Group in Switzerland.

Nicolas Maranzana is Assistant Professor at the Arts et Métiers ParisTech School of Engineering in Paris, France and a member of the Product Design and Innovation Laboratory (LCPI). His research interests focus on early stages of design process.

Améziane Aoussat received his PhD in New Product Design from Arts et Métiers ParisTech, Paris, France in 1990 and completed his Habilitation here in 1996. His field of research is the optimization of design and innovation processes. In particular, he is interested in 
the integration of new professions and skills and in the formalization of individual and collective design processes. He has published more than 62 articles in international journals, 12 international books and more than 151 contributions to international conferences. He is also reviewer for several international journals. He has directed $36 \mathrm{PhDs}$ and coordinated many national and international projects.

Giacomo Bersano is Chief Innovation Officer at IKOS Group, a leading consulting company in the field of transportation and energy. Here, he is in charge of knowledge management, research activity, training and external collaborations. In 2007, he created A.I.M., a company specialized in the resolution of complex problems and innovation management, with global players from the engineering, transportation and energy sectors as customers. He is also lecturer at ENSAM, Ecole de
Mines d'Ales, EPF and has various publications on inventive methods.

Stéphanie Buisine is a researcher in innovation at CESI School of Engineering in Paris. With a background in Psychology, Ergonomics and Human-Computer Interaction, her research interests include prospective methods, creativity process, and innovative organizations.

How to cite this article: Schöfer M, Maranzana N, Aoussat A, Bersano G, Buisine S. Distinct and combined effects of disciplinary composition and methodological support on problem solving in groups. Creat Innov Manag. 2018;27:102-115. https://doi.org/10.1111/caim.12258 